\title{
RESONANT BOUNDARY VALUE PROBLEMS FOR SINGULAR MULTI-TERM FRACTIONAL DIFFERENTIAL EQUATIONS
}

\author{
YUJi LiU AND XiAOHUI YANG
}

\begin{abstract}
In this article, we present and study three class of resonant boundary value problems for singular fractional differential equations with sup-multiplicative-like operators. The existence results for solutions of these boundary-value problems are established. Our analysis relies on the well known coincidence degree theory. Here the nonlinearity terms in fractional differential equations depend on $D_{0^{+}}^{\gamma} u$ and may be singular at $t=0$ or $t=1$. The results obtained generalize and enrich known results to some extent from the literature.
\end{abstract}

Mathematics subject classification (2010): 92D25, 34A08, 34B16, 47H10.

Keywords and phrases: solution, singular fractional differential equation, sup-multiplicative-like operator, coincidence degree theory, resonant boundary value problem.

\section{REFERENCES}

[1] T.S. Aleroev, H.T. Aleroeva, N. Nie, Y. TAng, Boundary value problems for differential equations of fractional order, Memoirs on Differential Equations and Mathematical Physics, 49 (2010), $21-82$.

[2] R.P. Agarwal, M. Benchohra, S. HAmAni, A survey on existence results for boundary value problems of nonlinear fractional differential equations and inclusions, Acta Appl. Math., 109 (2010), 973-1033, doi:10.1007/s10440-008-9356-6.

[3] A. Arara, M. Benchohra, N. Hamidi, J.J. Nieto, Fractional order differential equations on an unbounded domain, Nonlinear Analysis TMA, 72 (2010), 580-586, doi:10.1016/j.na.2009.06.106.

[4] B. Ahmad, J.J. Nieto, J. Pimentel, Some boundary value problems of fractional differential equations and inclusions, Computers and Mathematics with Applications, 62 (2011), 1238-1250, doi:10.1016/j.camwa.2011.02.035.

[5] B. Ahmad, S. Sivasundaram, Existence of solutions for impulsive integral boundary value problems of fractional order, Nonlinear Anal. Hybrid Syst., 4 (2010), 134-141, doi:10.1016/j.nahs.2009.09.002.

[6] Z. BAI, On positive solutions of a nonlocal fractional boundary value problem, Nonlinear Analysis, 72 (2010), 916-924, doi:10.1016/j.na.2009.07.033.

[7] Z. BAI, Solvability for a class of fractional m-point boundary value problem at resonance, Computers and Mathematics with Applications, 62 (2011), 1292-1302, doi:10.1016/j.camwa.2011.03.003.

[8] M. Benchohra, S. Hamani, J.J. Nieto, B.A. Slimani, Existence of solutions to differential inclusions with fractional order and impulses, Electron. J. Differ. Equ., 80 (2010), 1-18.

[9] Z. BAI, Y. ZHANG, The existence of solutions for a fractional multi-point boundary value problem, Computers and Mathematics with Applications, 60 (2010), 2364-2372, doi:10.1016/j.camwa.2010.08.030.

[10] Z. BAI, On solutions of some fractional m-point boundary value problems at resonance, Electronic Journal of Qualitative Theory of Differential Equations, 37 (2010), 1-15.

[11] A. CABADA, G. WANG, Positive solutions of nonlinear fractional differential equations with integral boundary value conditions, J. Math. Anal. Appl., 389 (2012), 403-411, doi:10.1016/j.jmaa.2011.11.065. 
[12] T. Chen, W. LIU, An anti-periodic boundary value problem for the fractional differential equation with a p-Laplacian operator, Appl. Math. Lett., 25, (2012), 1671-1675, doi:10.1016/j.aml.2012.01.035.

[13] T. Chen, W. LiU, Z. Hu, A boundary value problem for fractional differential equation with $p$-Laplacian operator at resonance, Nonlinear Analysis TMA, 75 (2012), 3210-3217, doi:10.1016/j.na.2011.12.020.

[14] R. Dehghant, K. Ghanbari, Triple positive solutions for boundary value problem of a nonlinear fractional differential equation, Bulletin of the Iranian Mathematical Society, 33 (2007), 1-14.

[15] K. Diethelm, The Analysis of Fractional Differential Equations: An Application-Oriented Exposition Using Differential Operators of Caputo Type, Springer Heidelberg Dordrecht London New York, 2010.

[16] W. FENG, J. R. L.WEBB, Solvability of three point boundary value problems at resonance, Nonlinear Anal., 30 (1997), 3227-3238, doi:10.1016/S0362-546X(96)00118-6.

[17] Z. HU, W. LiU, W. RuI, Periodic boundary value problems for fractional differential equations, International Journal of Math. 23 (2012) paper ID 1250100, 12 pages.

[18] G. L. Karakostas, Positive solutions for the $\Phi$-Laplacian when $\Phi$ is a sup-multiplicative-like function, Electron. J. Differ. Equ., 68 (2004), 1-12.

[19] N. Kosmatov, A boundary value problem of fractional order at resonance, Electron. J. Differ. Equ., 135 (2010), 1-10.

[20] A.A. Kilbas, H.M. SRivastaVa, J.J. Trujillo, Theory and applications of fractional differential equations, Elsevier B. V. Netherland, 2006.

[21] L. S. LeibEnSOn, General problem of the movement of acompressible fluid in a porous medium, Izvestiia Akademii Nauk Kirgizski SSSR, 9 (1983), 7-10.

[22] Y. LiU, Solvability of multi-point boundary value problems for multiple term Rieman-Liouville fractional differential equations, Computers and Mathematics with Applications, 64 (2012), 413-431, doi:10.1016/j.camwa.2011.12.004.

[23] Y. LiU, X. LiU, Existence of solutions of resonant boundary value problems for fractional differential equations, Differential Equations and Control Processes, 3 (2012), 70-90.

[24] Y. LiU, T. HE, H. SHI, Three positive solutions of Sturm-Liouville boundary value problems for fractional differential equations, Differ. Equ. Appl., 5 (2013), 127-152, doi:10.7153/dea-05-09.

[25] Z. LiU, L. LU, A class of BVPs for nonlinear fractional differential equations with p-Laplacian operator, Electronic Journal of Qualitative Theory of Differential Equations, 70 (2012), 1-16.

[26] C. Li, X. Luo, Y. Zhou, Existence of positive solutions of the boundary value problem for nonlinear fractional differential equations, Comput. Math. Appl., 59 (2010), 1363-1375, doi:10.1016/j.camwa.2009.06.029

[27] J. MAWHIN, Topological degree methods in nonlinear boundary value problems, in: NSFCBMS Regional Conference Series in Math., American Math. Soc. Providence, RI, 1979.

[28] J. MU, H. FAn, Positive mild solutions of periodic boundary value problems for fractional evolution equations, Journal of Applied Mathematics, 2012 (2012), Article ID 691651, 13 pages, doi:10.1155/2012/691651.

[29] K.S. Miller, B. Ross, An Introduction to the Fractional Calculus and Fractional Differential Equation, Wiley, New York, 1993.

[30] J.J. NiETO, Comparison results for periodic boundary value problems of fractional differential equations, Fractional Differential Calculus, 1 (2011), 99-104.

[31] Z. OUYAnG, G. LI, Existence of the solutions for a class of nonlinear fractional order threepoint boundary value problems with resonance, Boundary Value Problems, 68 (2012), 68 pages, doi:10.1186/1687-2770-2012-68.

[32] S.Z. Rida, H.M. El-Sherbiny, A.A.M. Arafa, On the solution of the fractional nonlinear Schrödinger equation, Physics Letters A, 372 (2008), 553-558, doi:10.1016/j.physleta.2007.06.071.

[33] H.A.H. SALEM, Fractional order boundary value problem with integral boundary conditions involving Pettis integral, Acta Math. Sci. Ser. B Engl. Ed. 31, (2) (2011), 661-672, doi:10.1016/S02529602(11)60266-X.

[34] S.G. Samko, A.A. Kilbas, O.I. Marichev, Fractional Integral and Derivative. Theory and Applications, Gordon and Breach, 1993. 
[35] Y. TIAN, Z. BAI, Existence results for the three-point impulsive boundary value problem involving fractional differential equations, Computers and Mathematics with Applications, 59 (2010), 26012609, doi:10.1016/j.camwa.2010.01.028.

[36] X. TANG, C. YAN, Q. LIU, Existence of solutions of two-point boundary value problems for fractional p-Laplace differential equations at resonance, Journal of Applied Mathematics and Computing, 41 (2013), 119-131.

[37] Z. WeI, W. Dong, Periodic boundary value problems for Riemann-Liouville sequential fractional differential equations, Electronic Journal of Qualitative Theory of Differential Equations, 87 (2011), $1-13$.

[38] Z. WeI, W. Dong, J. CHE, Periodic boundary value problems for fractional differential equations involving a Riemann-Liouville fractional derivative, Nonlinear Analysis: TMA, 73 (2010), 3232 3238, doi:10.1016/j.na.2010.07.003.

[39] X. XU, D. JiAng, C. YUAn, Multiple positive solutions for the boundary value problem of a nonlinear fractional differential equation, Nonlinear Analysis TMA, 71 (2009), 4676-4688, doi:10.1016/j.na.2009.03.030.

[40] F. ZHANG, Existence results of positive solutions to boundary value problem for fractional differential equation, Positivity, 13 (2008), 583-599.

[41] Y. ZHANG, Z. BAI, Existence of solutions for nonlinear fractional three-point boundary value problems at resonance, Journal of Applied Mathematics and Computing, 36 (2011), 417-440, doi:10.1007/s12190-010-0411-x.

[42] Y. ZHANG, Z. BAI, T. FENG, Existence results for a coupled system of nonlinear fractional threepoint boundary value problems at resonance, Computers and Mathematics with Applications, 61 (2011), 1032-1047, doi:10.1016/j.camwa.2010.12.053. 